\section{Comparison of Four Methods for Estimating Total Light Interception by Apple Trees of Varying Forms}

\author{
Jens N. Wünsche ${ }^{1}$ \\ Institut für Obstbau und Gemüsebau, Universität Bonn, Auf dem Hügel 6, \\ 53121 Bonn, Germany
}

\author{
Alan N. Lakso ${ }^{2}$ and Terence L. Robinson ${ }^{3}$ \\ Department of Horticultural Sciences, Cornell University, New York State \\ Agricultural Experiment Station, Geneva, NY 14456
}

Additional index words. ceptometer, fisheye photography, Malus domestica, quantum sensor

\begin{abstract}
Four methods of estimating daily light interception (fisheye photography with image analysis, multiple-light sensors, ceptometer, and point grid) were compared using various apple (Malus domestica Borkh.) tree forms: slender spindle, Y-and T-trellises, and vertical palmette. Interactions of tree form, time of day, and atmospheric conditions with light interception estimates were examined. All methods were highly correlated to each other $\left(r^{2}>0.92\right)$ for estimated daily mean percent total light interception by the various tree forms, except that the point grid method values were slightly lower. Interactions were found among tree form, time of day, and diffuse/direct radiation balance on estimated light interception, suggesting that several readings over the day are needed under clear skies, especially in upright canopies. The similar results obtained by using the point grid method (counting shaded/exposed points on a grid under the canopy) on clear days may allow rapid, simple, and inexpensive estimates of orchard light interception.
\end{abstract}

The interception and use of sunlight, or more accurately, photosynthetic photon flux (PPF) (400 to $700 \mathrm{~nm}$ ), by orchard systems form the basis of potential total dry matter and fruit productivity of these systems (Jackson, 1980; Lakso, 1994; Palmer, 1989; Robinson and Lakso, 1991). Therefore, knowledge of total light interception in differing orchard systems is needed to help understand the basis of differences in orchard yield and fruit quality. The term "light" is used in a more general sense, but it refers to PPF as measured by the two quantum sensors used and to visible light in the fisheye photography and point grid methods.

Several modeling approaches have been produced to estimate total light interception of various orchard designs or tree forms (Johnson and Lakso, 1990; Palmer, 1989). The use of computer models enables rapid calculations

\footnotetext{
Received for publication 11 July 1994. Accepted for publication 7 Dec. 1994. This research was funded in part by Gottlieb Daimler-und Karl Benz-Stiftung, Ladenburg, Germany. Use of trade names does not imply endorsement of the products named nor criticism of similar ones not named. The cost of publishing this paper was defrayed in part by the payment of page charges. Under postal regulations, this paper therefore must be hereby marked advertisement solely to indicate this fact.

${ }^{1}$ Visiting Scientist; to whom reprint requests should be addressed.Current address: The Horticulture and Food Research Institute of New Zealand, Riwaka Research Centre, Old Mill Rd., RD3 Motueka, New Zealand.

${ }^{2}$ Professor.

${ }^{3}$ Associate Professor.
}

with reasonable accuracy and allows evaluation of general effects of orchard design (various geometric tree forms, tree sizes, tree spacings, pruning and training practices) on light interception and distribution. However, approaches to modeling light interception are based on several assumptions and simplify reality; thus, they cannot easily describe the light interception of actual orchards.

The accurate estimation of light interception in real discontinuous canopy orchards requires integration of light readings over time and space. Several methods have been used to describe total tree light interception or microclimate within tree canopies under field conditions. Photochemical methods have been used to quantify the light climate within apple canopies, but problems of sensitivity, radiation geometry of tubes, and linearity with accumulated light have limited their use (Avidan and Erez, 1986; Heinicke, 1963; Maggs and Alexander, 1970). More accurate electronic light sensors with selenium or silicon cells have been used widely to estimate total light interception and light distribution in orchard systems by using single-point sensors (Barritt et al., 1991; Jackson, 1980; Palmer, 1987, 1988) as well as line or tube sensors, respectively (Agha and Buckley, 1986; Wagenmakers and Callesen, 1989). These methods normally require a grid of sensors that integrate over time; or, as a simplification, sensors are moved quickly to various grid positions and repeat readings over time. Although these methods can be accurate under the prevailing conditions, they may require considerable expense for sensors, dataloggers, or operator time. Also, if the readings are taken under cloudy conditions, the results may not be the same as under clear conditions. Fisheye or hemispherical photography is an indirect method based on photographing the tree canopy and then modeling, via image analysis software, how the canopy modifies the light availability at the point of the photograph (Anderson, 1971). Besides estimating light interception, this method can provide powerful additional information about estimates of 1) several components of the light microclimate (Anderson, 1964; Lakso, 1980); 2) light environment-related plant performance (Chazdon and Field, 1987; Lakso, 1980; Walters and Field, 1987); and 3) several components of canopy structure, such as leaf area index, leaf angle distribution (Anderson, 1971), gap frequency, and sunlit foliage area (Bonhomme and Chartier, 1972). Fisheye photography was first used in horticulture by Smart (1973) in vineyards and since has been adapted and further developed and validated for orchards (Ferree and Lakso, 1979; Kappel et al., 1983; Lakso, 1976, 1980; Robinson and Lakso, 1989, 1991; Schechter et al., 1990). This method has the advantage of evaluating real canopies, but allows modeling light microclimate under a range of conditions (the images can be rotated to determine if canopies interact with orientation, or differing balances of diffuse and direct incident light can be used). Photographs can be taken quite quickly. Disadvantages include time of processing and analysis and cost or availability of image analysis systems.

Consequently, a need exists for a comparison of several of these techniques and methods for estimating total light interception on one set of trees of varying tree forms at one time. The objectives of this study were to 1) compare four methods (fisheye photography, multiple-light sensors, ceptometer, and a point grid) for relative estimates of total light interception and time efficiency of the sampling process; and 2) evaluate any interactions of tree form, weather conditions (completely overcast vs. completely clear sky), and time of day with light interception estimates by each method.

\section{Materials and Methods}

A 15-year-old experimental 'Empire' apple orchard at the New York State Agricultural Experiment Station, Geneva, with four tree forms was used to compare various methods for estimates of total light interception: slender spindle (pyramid), Y-trellis (Y-shaped hedgerow), T-trellis (horizontal T-shaped hedgerow), and palmette (thin, vertical hedgerow).

Slender spindles were grafted on M.9 and planted in a tree spacing of $1.7 \times 5.5 \mathrm{~m}(1087$ trees/ha), while the other three forms were on interstem M.9/MM.111 at $2.4 \times 5.5 \mathrm{~m}$ (749 trees/ha). This tree form experimental trial had wider spacings than normally used in dwarfing apple orchards; thus, the maximum total tree light interceptions could be expected to be lower than for similar tree forms in commercial planting orchards. The distance between rows avoided row-to-row direct-light shading during the measurements. 
For each tree form, three representative trees were selected for uniformity of form and canopy density, giving a total of 12 trees of varying forms estimated for each method. Multiple-light sensors, ceptometer line sensor, fisheye photography, and a point grid were used for estimating total light interception.

Multiple-light sensors. Cosine-corrected quantum sensors (LI-190SZ; LI-COR, Lincoln, Neb.) were attached to a datalogger $(21 \mathrm{X}$ Micrologger; Campell Scientific, Logan, Utah). Nine equally spaced, single-light sensors were mounted on a horizontal bar of a small trailer with the bar length adjusted to extend from the middle of the tree row to the center of the alleyway. A tenth light sensor was attached to a vertical metal pole and held horizontally over the tree canopy to record $100 \%$ of incident light. The trailer was positioned at 10 various locations underneath the canopy, on each side of the test tree at the trunk, halfway and quarter-way toward the adjacent trees, respectively (Fig. 1A). At each location, a simultaneous reading was taken from each of the 10 sensors. Thus, for each test tree, 90 below-canopy readings in a grid pattern and 10 above-canopy, open-sky readings were taken. The light readings were taken three times a day at $\approx 2$ to $3 \mathrm{~h}$ before solar noon, at solar noon, and 2 to $3 \mathrm{~h}$ after solar noon on completely cloudy, overcast days, and on sunny, clear days. Light interception per tree was estimated by calculating for each belowcanopy reading the percentage of the abovecanopy reading (i.e., transmission), and then by subtracting the average percentage transmission of all 90 sensor readings from $100 \%$ (total incident light).

Ceptometer. The ceptometer (model SF80; Decagon Devices, Pullman, Wash.) was used as a PPF line sensor that integrated readings of 80 light sensors placed at $1-\mathrm{cm}$ intervals along an $80-\mathrm{cm}$-long probe, similar in concept to the line of single sensors. A microprocessor recorded an average value of all sensors along the probe at each reading. Thirty below-canopy readings, 15 on each tree side, and one above-canopy, open-sky reading were taken for each test tree. Thus, six readings were taken across the row from alley center to alley center at each of five within-row locations: at the trunk of the test tree and halfway and quarter-way toward the adjacent trees, respectively (Fig. 1B). A bubble level on the ceptometer and a support rod on the probe end were used to hand-position the probe horizontally to the orchard floor. All readings were taken under the same sunny and overcast conditions and times of day as the multiple-lightsensor method. Light interception per tree was calculated as described for the multiple-light sensors.

Fisheye photography. Fisheye photography was used similar to the methods described by Lakso (1976) and Robinson and Lakso (1991). Complete grids of vertical hemispherical photographs were taken underneath the tree canopies either under overcast conditions or very early or late in the day to improve contrast and to avoid a direct sunlight spot on
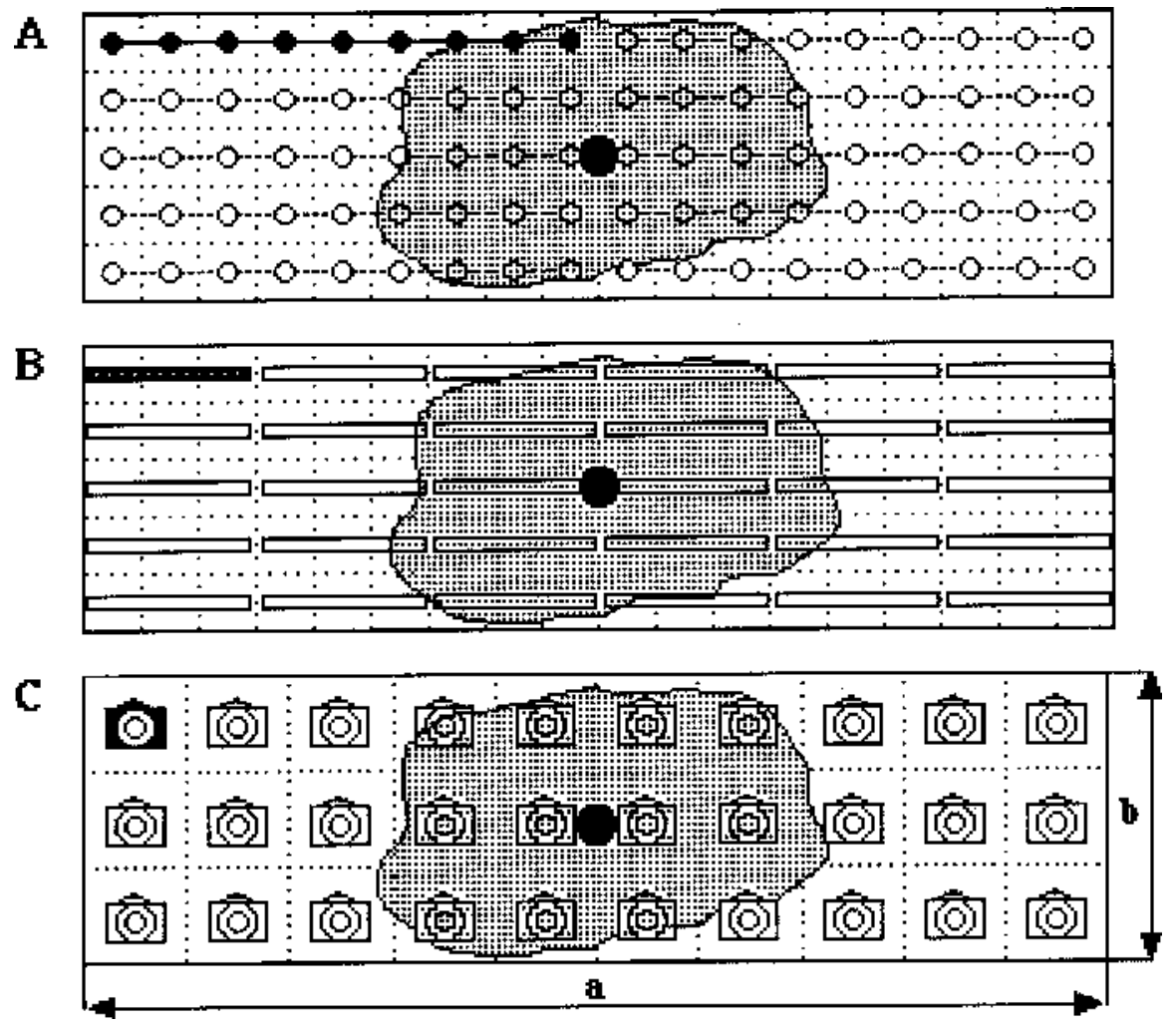

Fig. 1. Size of measurement area and arrangements of light meters for estimates of total light interception in orchard systems. (A) Multiple-light sensors, (B) ceptometer, and (C) fisheye camera were arranged on a below-tree canopy grid that reached in each direction the midpoint between the test tree and its adjacent trees; (a) across rows from alley center to alley center and (b) in rows halfway to the adjacent trees. The trunk was taken as the center point of the grid pattern.

the film. The camera was mounted on a short tripod with the film plane positioned horizontally and the lens pointing vertically upward at $20 \mathrm{~cm}$ above the orchard floor. The land area allocated per tree (row $\times$ tree spacing) was divided into equal areas, and the pictures were taken in the center of these areas (Fig. 1C). Twenty pictures for slender spindle and 30 pictures for the other three tree forms, due to the larger area allocated per tree, were taken per tree. Photographs were analyzed by digitizing the negative image via a computercontrolled Gould DeAnza Image Analysis System and estimating full-sky diffuse and solar-track direct visible radiation (photosynthetically active radiation) with the procedure described by Robinson and Lakso (1991).

Point grid. A simplified modification of the point quadrat method (Warren Wilson, 1960), called here the point grid, was also used. The method records direct sunlight beams that penetrate through the tree canopy under sunny conditions and strike a white sheet (or flat surface) with grid points laid on the orchard floor in the area allotted to the tree. Counting the points in the shadow of the tree vs. points in the sun provides a rapid and inexpensive method for estimating direct-light interception. Since this method only estimates direct-beam interception, errors may occur if the direct- and diffuse-light interception percentages are different, as in some east-west planar canopies at low latitudes. This method could only be used on days bright enough to produce well-defined shadows. In this study, a white plastic sheet with black grid points spaced at $30 \times 30 \mathrm{~cm}$ was laid underneath the canopy over the entire area allocated per tree. Points in the shadow cast by the tree were counted in the morning, at noon, and in the afternoon on a clear day. Mean daily total light interception was estimated as an average of the percentage of points (176 for slender spindle and 220 for the other three tree forms) in shade during the three sampling times.

All methods were tested in late August, after the cessation of shoot growth and leaf area development. Because of the dependence on suitable weather conditions, not all light readings could be performed on the same day, but were completed within a few days. All methods, except the point grid, give estimates of light available at the location of the measurement.

\section{Results}

Estimates of the daily mean percent total light interception by the four tree forms were similar whether fisheye photography, multiple-light sensors, or the ceptometer was used. However, the mean of the point grid method for PPF intercepted was slightly, but not significantly, lower (Table 1). These values were based on three readings per day on all methods, except the fisheye photography, which estimates interception at 15-min intervals. No interactions with tree form were found.

Regressions among the four methods comparing estimates of daily mean percent total 
Table 1. Comparison of four methods for estimating daily mean percent total photosynthetic photon flux (PPF) interception by four tree forms.

\begin{tabular}{lcccc}
\hline \hline & \multicolumn{4}{c}{ Total PPF interception $(\%)^{\mathrm{z}}$} \\
\cline { 2 - 5 } Tree form & Point grid & Ceptometer & $\begin{array}{c}\text { Multiple-light } \\
\text { sensors }\end{array}$ & $\begin{array}{c}\text { Fisheye } \\
\text { photographs }\end{array}$ \\
\hline T-trellis & $26 \mathrm{a}^{y}$ & $32 \mathrm{a}$ & $33 \mathrm{a}$ & $32 \mathrm{a}$ \\
Y-trellis & $38 \mathrm{~b}$ & $46 \mathrm{a}$ & $45 \mathrm{a}$ & $42 \mathrm{ab}$ \\
Slender spindle & $37 \mathrm{a}$ & $42 \mathrm{a}$ & $41 \mathrm{a}$ & $39 \mathrm{a}$ \\
Palmette & $20 \mathrm{a}$ & $24 \mathrm{a}$ & $24 \mathrm{a}$ & $22 \mathrm{a}$ \\
Grand mean & $30 \mathrm{a}$ & $36 \mathrm{a}$ & $36 \mathrm{a}$ & $34 \mathrm{a}$ \\
\hline
\end{tabular}

${ }^{2}$ Values are means of three replicate trees estimated by using 1) multiple-light sensors and ceptometer under completely overcast and clear sky at $\approx 2$ to $3 \mathrm{~h}$ before solar noon, solar noon, and 2 to $3 \mathrm{~h}$ after solar noon; 2) point grid under completely clear sky at the same sampling times; and 3) fisheye photography and image analysis.

${ }^{y}$ Mean separation within each tree form by Tukey's HSD test $(P \leq 0.05)$.
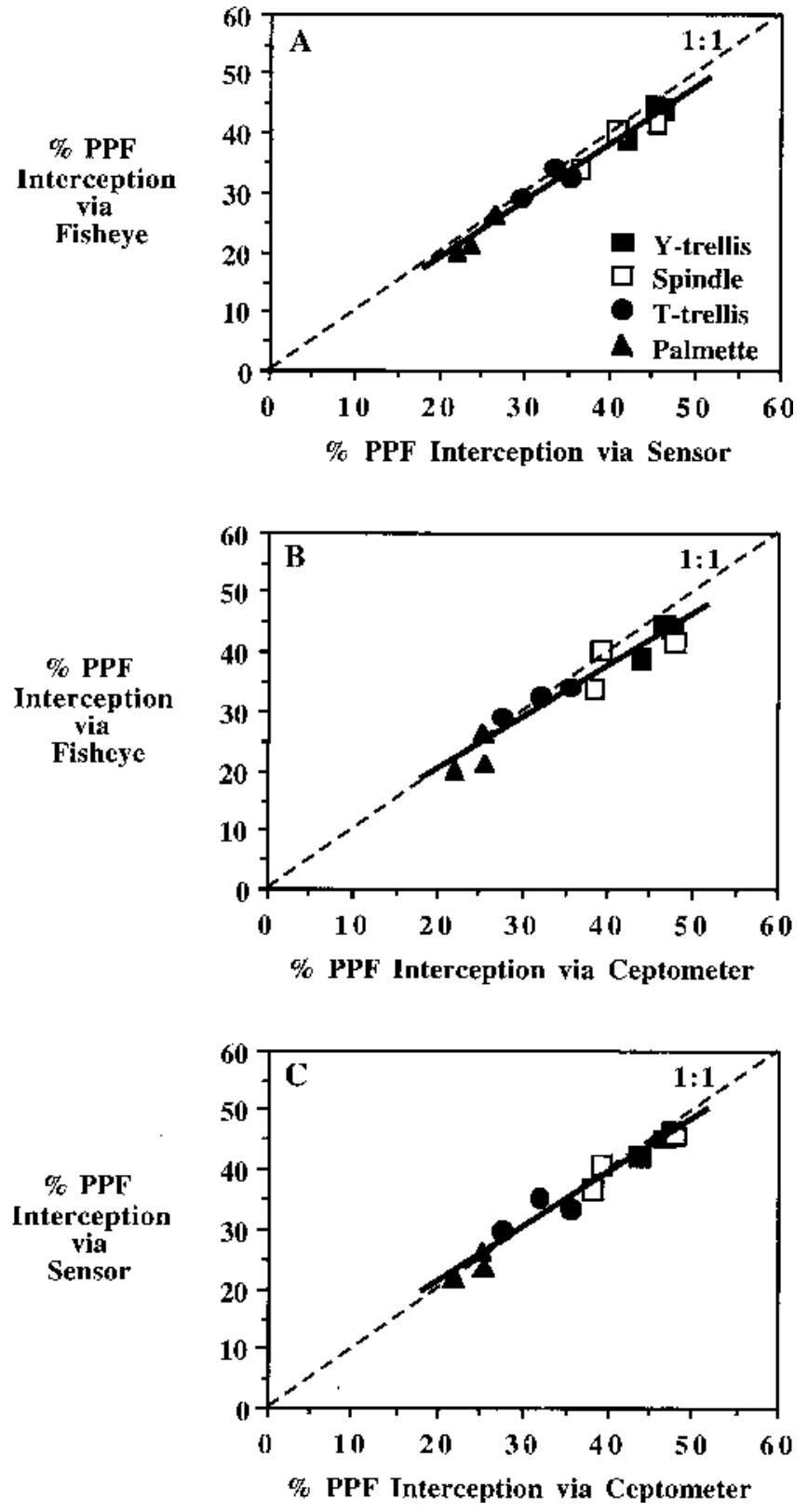

Fig. 2. Relationship of daily mean percent total photosynthetic photon flux interception by 12 trees of four tree forms estimated by using 1) multiple-light sensors and ceptometer under completely overcast and clear sky conditions at $\approx 2$ to $3 \mathrm{~h}$ before solar noon, solar noon, and 2 to $3 \mathrm{~h}$ after solar noon and 2 ) fisheye photography and image analysis. The regression equations were (A) fisheye vs. sensor, $\mathrm{y}=-0.192+$ $0.957 \mathrm{x}\left(r^{2}=0.97\right) ;(\mathbf{B})$ fisheye vs. ceptometer, $\mathrm{y}=2.858+0.862 \mathrm{x}\left(r^{2}=0.92\right) ;(\mathbf{C})$ sensor vs. ceptometer, $\mathrm{y}=3.024+0.905 \mathrm{x}\left(r^{2}=0.96\right)$. light interception by the 12 trees of various forms showed good agreement (Figs. 2 and 3). When comparing fisheye photography, multiple-light sensors, and the ceptometer, the slopes were near the 1:1 line, with intercepts near zero, indicating good comparability among methods (Fig. 2). Comparing the point grid with the other three methods, the regressions were off the 1:1 line by about five percentage points (Fig. 3). This result indicates an underassessment of light interception via the point grid method, assuming the other methods are truer estimates.

For these north-south-oriented tree rows, the estimated amount of light intercepted by the tree canopies was affected by the time of day and the weather conditions under which the measurements were taken (Fig. 4). The effect of time of day on tree light interception could not be evaluated by using fisheye photography since only whole-day mean values were recorded, although software could be modified. We assumed that a diurnal analysis of fisheye photography, due to comparable estimates of daily mean percent light interception with multiple-light sensors and the ceptometer, would basically lead to similar results.

Under completely clear sky with $\approx 85 \%$ direct radiation, the estimated percent light interception over a day interacted strongly with tree form, and all tested methods generated a tree-form-specific diurnal light interception pattern (Fig. 4A). As expected, the time-of-day effect on light interception on clear days was slight for horizontal T- and Ytrellis canopies, more pronounced with triangular slender spindle canopies, and most pronounced with thin, vertical palmette canopies (Fig. 4A). Therefore, for triangular and vertical tree forms, the time of day when measurements are taken is clearly an important consideration, and several readings per day should be taken. Under completely overcast sky with mostly diffuse radiation, daily variations in total light interception by all four tree forms were relatively small as measured by the multiple-light sensors, but somewhat more pronounced with the ceptometer (Fig. 4B).

\section{Discussion}

All methods compared appeared to be suitable for estimating total daily light interception by various tree forms, as the correlation among them was high when the means of three readings per day were used. However, all methods had inherent advantages and disadvantages.

We assume that truer estimates of total light interception were given by the similar values of the two light sensor methods and the fisheye photography compared to the point grid method. The use of the point grid requires some further considerations. Due to the apparently slight but consistent underestimates of total light interception, a correction factor would be necessary for more accurate estimates. The underestimate appears to be due to the yes/no nature of the decision of sun or shade at each point, which essentially ignores 

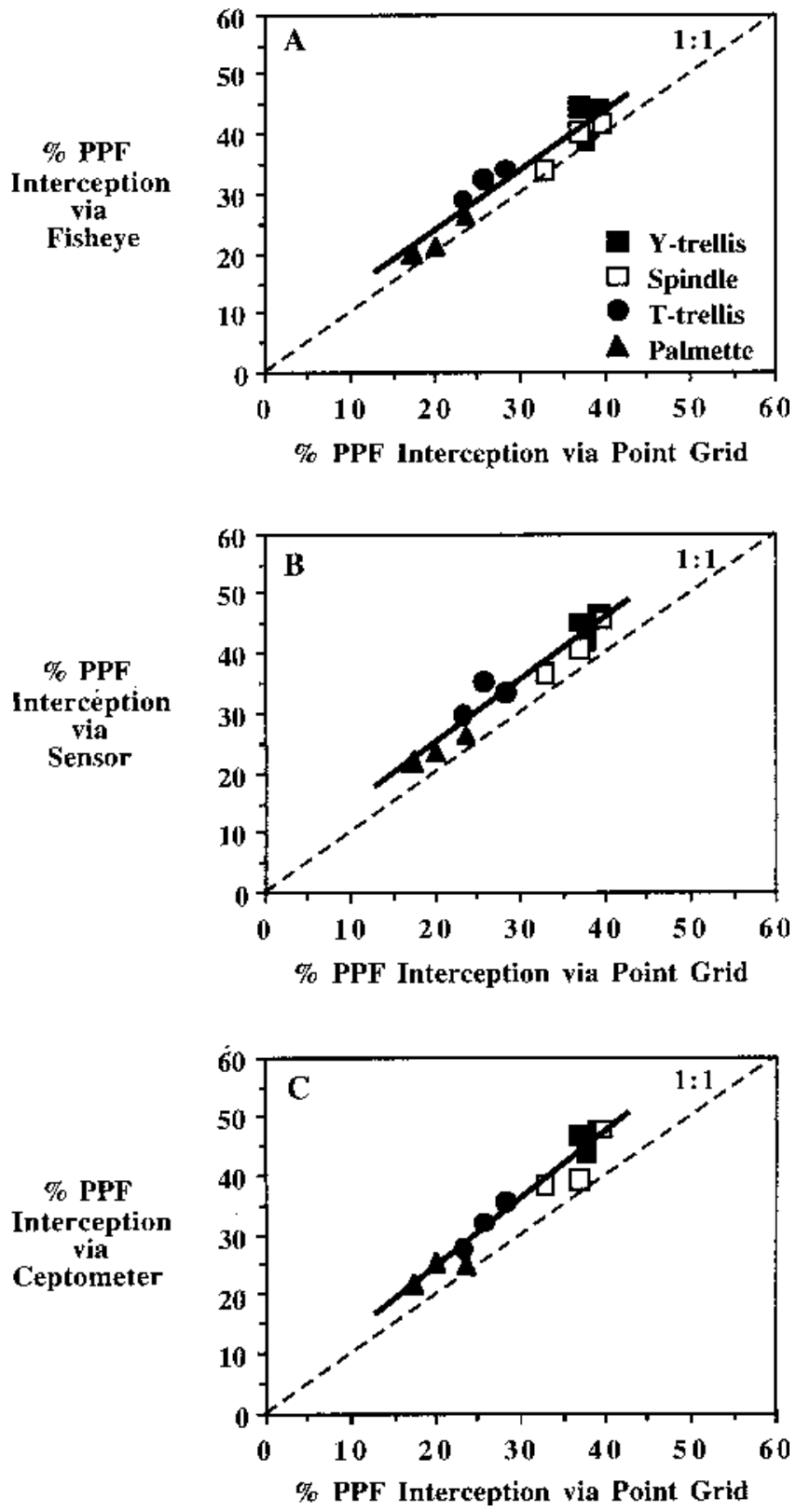

Fig. 3. Relationship of daily mean percent total photosynthetic photon flux interception by 12 trees of four tree forms estimated by the point grid under clear sky conditions vs. fisheye photography (A), multiplelight sensors $(\mathbf{B})$, and ceptometer $(\mathbf{C})$ under overcast and clear sky conditions at $\approx 2$ to $3 \mathrm{~h}$ before solar noon, solar noon, and 2 to $3 \mathrm{~h}$ after solar noon. The regression equations were $(\mathbf{A}) \mathrm{y}=3.636+1.002 \mathrm{x}$ $\left(r^{2}=0.92\right) ;(\mathbf{B}) \mathrm{y}=4.031+1.046 \mathrm{x}\left(r^{2}=0.94\right) ;(\mathbf{C}) \mathrm{y}=1.753+1.135 \mathrm{x}\left(r^{2}=0.95\right)$.

diffuse light transmission and estimates only direct-light transmission. The consistency of the relationship of the point grid to the other methods (Fig. 3) gives some confidence in the use of a correction factor. Sampling error could be adjusted by changing the number of grid points per unit area. Nevertheless, the point grid technique represents a rapid ( $5 \mathrm{~min} /$ tree), easy-to-use, easy-to-teach, and inexpensive method for estimating light interception, especially for relative comparisons of orchard systems.

Compared to the multiple-light sensors, the ceptometer was less awkward to handle and allowed a fast sampling time $(10 \mathrm{~min} /$ tree). Using a bar of single-light sensors required more time for mounting the sensors on the trailer bar, positioning the trailer underneath the canopy, leveling the sensors at each position, and positioning the sensor above the tree canopy. The sampling process required $\approx 15 \mathrm{~min} /$ tree. A disadvantage for both methods is the dependence on the weather conditions since best results are obtained on either uniformly clear days or overcast days. The daily variation in total tree light interception under overcast conditions was more pronounced with the ceptometer than with the multiple-light sensors (Fig. 4B), likely due to the lower frequency of above-canopy readings. Under overcast, or especially partly cloudy, conditions, the incident radiation can change significantly within a short period. For the ceptometer, only one open-sky reading was taken per tree, whereas for the multiplelight sensors, each of the 10 open-sky readings per tree was taken simultaneously with a set of below-canopy readings. To reduce this extra sampling error with the ceptometer, the opensky readings should be either taken more often or recorded frequently by a separate sensor with a synchronized datalogger. Additionally, since the ceptometer is hand-held, the operator must take care to avoid blocking direct or diffuse light when taking readings. This caution does not apply, or only to a much lesser extent, to the multiple-light sensors since the operator can stay farther from them.

Although the uses and utility of hemispherical photography are clear, the computerized fisheye image analysis is quite timeconsuming, requiring up to $5 \mathrm{~min} /$ photograph, depending on the program and system used. With an average of 25 pictures taken per tree, the total processing time per tree was $\approx 2 \mathrm{~h}$. Manual analysis of the photographs can, however, consume much more time (Anderson, 1971). Because of the amount of time spent for fisheye image analysis, other techniques should be considered first if the only interest is estimating total light interception. Furthermore, fisheye photography should only be used under overcast conditions, although photos may be taken either early in the morning or late afternoon when the sun is not in the image. The time requirement for taking the photographs in the field was similar to the sensor method, $\approx 15 \mathrm{~min} /$ tree.

Our results indicate that light interception is affected by tree form, time of day, and current weather conditions (Fig. 4). Since under overcast sky, variations in light interception seem to be insignificant for all four tree forms (Fig. 4B), one single set of light readings may be adequate for estimates of daily mean light interception if the trees intercept about the same amount of diffuse light as direct light, the case in many, but not all, orchards. Under clear sky conditions, the light readings are much more influenced by tree form and time of day (Fig. 4A). Although a single set of light readings on a clear, sunny day seems to be sufficient for estimates of daily mean light interception by horizontal canopies, more sets of readings over the day are desirable to decrease the sampling error for more-vertical tree canopies that are parallel to the high solar elevation angles. To a lesser extent, the same is true for slender spindle canopies.

In summary, all four methods were highly correlated to each other for estimated daily mean percent total light interception by the various tree forms, although point grid values were about five percentage points lower. Under overcast sky, daily variations in total light interception were small for all tree forms. However, under clear sky, the time-of-day effect on light interception strongly increased from horizontal to vertical tree canopies, indicating the importance of several readings in time in upright canopies. The point grid method is useful for estimates of orchard light interception when other methods are too costly or time-consuming. 
A - Completely Clear Sky

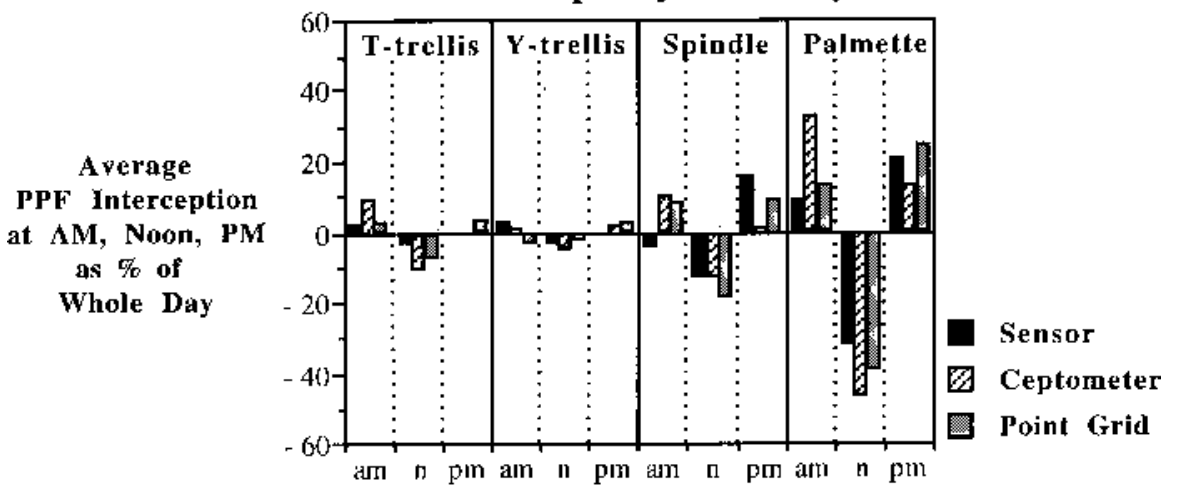

B - Completely Overcast Sky

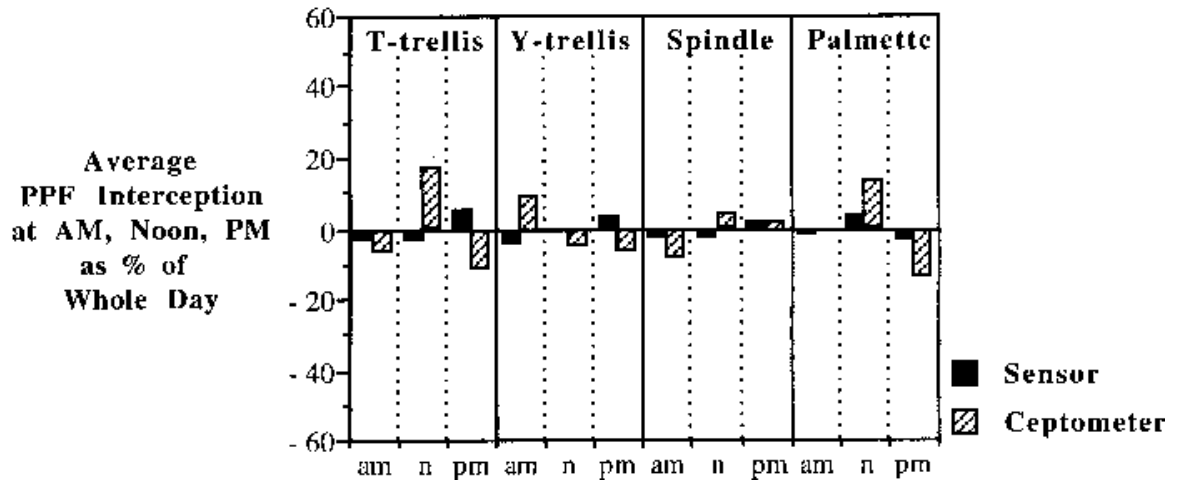

Fig. 4. Comparison of methods for estimating mean percent total photosynthetic photon flux interception by four tree forms at $\approx 2$ to $3 \mathrm{~h}$ before solar noon, solar noon, and 2 to $3 \mathrm{~h}$ after solar noon as a percentage of whole-day average under clear sky conditions by using (A) multiple-light sensors, the ceptometer, and the point grid method and under overcast sky conditions by using (B) multiple-light sensors and the ceptometer. Values are means of three replicate trees.

\section{Literature Cited}

Agha, N.S.A. and W.R. Buckley. 1986. Assessment of canopy efficiency of apple trees in beds. 1 . Canopy development assessed by direct light measurements. J. Hort. Sci. 61:153-159.

Anderson, M.C. 1964. Studies of the woodland light climate. I. The photographic computation of light conditions. J. Ecol. 52:27-41.

Anderson, M.C. 1971. Radiation and crop structure, p. 412-466. In: Z. Sestak, J. Catsky, and P.G. Jarvis (eds.). Plant photosynthetic production: Manual of methods. W. Junk Publ., The Hague, The Netherlands.

Avidan, B. and A. Erez. 1986. A reliable actinometricmethodforcharacterizing the light regime in plant canopies. J. Amer. Soc. Hort. Sci. 111:187-191.
Barritt, B.H., C.R. Rom, B.J. Konishi, and M.A. Dilley. 1991. Light level influences spur quality and canopy development and light interception influence fruit production in apple. HortScience 26:993-999.

Bonhomme, R. and P. Chartier. 1972. The interpretation and automatic measurement of hemispherical photographs to obtain sunlit foliage area and gap frequency. Israeli J. Agr. Res. 22:53-61.

Chazdon, R.L. and C.B. Field. 1987. Photographic estimation of photosynthetically active radiation: Evaluation of a computerized technique. Oecologia (Berlin) 73:525-532.

Ferree, D.C. and A.N. Lakso. 1979. Effect of selected dormant pruning techniques in a hedgerow apple orchard. J. Amer. Soc. Hort. Sci. 104:736739
Heinicke, D.R. 1963. The microclimate of fruit trees. I. Light measurements with uranyl oxalate actinometers. Can. J. Plant Sci. 43:561-568.

Jackson, J.E. 1980. Light interception and utilization by orchard systems. Hort. Rev. 2:208-267.

Johnson, R.S. and A.N. Lakso. 1990. Approaches to modeling light interception. HortScience 26:1002-1004.

Kappel, F., J.A. Flore, and R.E.C. Layne. 1983. Characterization of the light microclimate in four peach hedgerow canopies. J. Amer. Soc. Hort. Sci. 108:102-105.

Lakso, A.N. 1976. Characterizing apple tree canopies by fisheye photography. HortScience 11:404-405.

Lakso, A.N. 1980. Correlation of fisheye photography to canopy structure, light climate, and biological responses to light in apple trees. J. Amer. Soc. Hort. Sci. 105:43-46.

Lakso, A.N. 1994. Environmental physiology of the apple, p. 3-42. In: B. Schaffer and P.C. Andersen (eds.). Environmental physiology of fruit crops, vol. 1. Temperate crops. CRCPress, Boca Raton, Fla.

Maggs, D.H.and D.M.C.E. Alexander. 1970. Tests of a uranyl oxalate light integrator for use in fruit tree canopies. J. Appl. Ecol. 7:639-646.

Palmer, J.W. 1987. A simple, robust lightmeter for measuring light in orchards. J. Hort. Sci. 62:14.

Palmer, J.W. 1988. Annual dry matter production and partitioning over the first five years of a bed system of Crispin/M.27 apple trees at four spacings. J. Appl. Ecol. 25:569-578.

Palmer, J.W. 1989. Canopy manipulation for optimum utilisation of light, p. 245-262. In: C.J. Wright (ed.). Manipulation of fruiting. Butterworths, London.

Robinson, T.L. and A.N. Lakso. 1989. Light interception yield and fruit quality of 'Empire' and 'Delicious' apple trees grown in four orchard systems. Acta Hort. 243:175-184.

Robinson, T.L. and A.N. Lakso. 1991. Bases of yield and production efficiency in apple orchard systems. J. Amer. Soc. Hort. Sci. 116:188-194.

Schechter, I., D.C. Elfving, and J.T.A. Proctor. 1991. Apple tree canopy development and photosynthesis as affected by rootstock. Can. J. Bot. 69:295-300.

Smart, R.E. 1973. Sunlight interception by vineyards. Amer. J. Enol. Viticult. 4:141-147.

Wagenmakers, P.S. and O. Callesen. 1989. Influence of light intercepion on apple yield and fruit quality related to arrangement and tree height. Acta Hort. 243:149-158.

Walters, M.B. and C.B. Field. 1987. Photosynthetic light acclimation in two rainforest Piper species with different ecological amplitudes. Oecologia (Berlin) 72:449-456.

Warren Wilson, J. 1960. Inclined point quadrats. New Phytol. 59:1-8. 